\title{
COX-2 inhibitors sensitize human hepatocellular carcinoma cells to TRAIL-induced apoptosis
}

\author{
YUTAKA YAMANAKA, KATSUYA SHIRAKI, TOMOKO INOUE, KAZUMI MIYASHITA, HIROYUKI FUKE, \\ YUMI YAMAGUCHI, NORIHIKO YAMAMOTO, KEIICHI ITO, KAZUSHI SUGIMOTO and TAKESHI NAKANO
}

First Department of Internal Medicine, Mie University School of Medicine, 2-174 Edobashi, Tsu, Mie, Japan

Received January 31, 2006; Accepted March 27, 2006

\begin{abstract}
Cyclooxygenase (COX)-2 is upregulated in a variety of human cancers, including in hepatocellular carcinoma (HCC), whereas it is undetectable in most normal tissue. Evidence suggests that COX-2 is likely to be involved in hepatocarcinogenesis and, thus, COX-2 may be involved in an early process in carcinogenesis, dedifferentiation. To address this possibility, we investigated the effect of COX-2 inhibitors on TNF-related apoptosis, inducing ligand (TRAIL) sensitivity and its molecular mechanisms, with special attention to anti-apoptotic proteins. We used the highly selective COX-2 inhibitors, NS398 and CAY10404. We also used the MTT assay and cytological analysis of DAPI-stained DNA to assess viability and apoptosis in two HCC cells (SKHep 1 and HLE). In order to ask what led to increased sensitivity to TRAIL in HCC cells, cell surface expression of TRAIL and TRAIL-receptors was investigated using flow cytometry analysis. Expression of survivin, X-chromosomelinked IAP (XIAP), Bcl-xL, AKT and phospho-AKT was also investigated using immunoblotting. COX-2 inhibitors resulted in a concentration-dependent decrease in cell viability in the two HCC cell lines tested. Subtoxic levels of COX-2 inhibitors did not significantly augment TNF $\alpha$-induced apoptosis but did dramatically enhance TRAIL-induced apoptosis in both cell lines. TRAIL receptor $2 /$ death receptor 5 (TRAIL-R2/DR5) expression was significantly up-regulated in SH-Hep1 and HLE cells. TRAIL receptor 1/death receptor 4 (TRAIL-R1/DR4) expression was up-regulated only in SKHep1. Expression of survivin and Bcl-xL was down-regulated in SK-Hep1 and HLE cells in the presence of CAY10404 but XIAP was not affected. Expression of survivin, Bcl-xL and XIAP was down-regulated in SK-Hep1 cells in the presence of NS398. Survivin expression was also down-regulated in the presence of NS398 in HLE cells. Finally, NS398 also
\end{abstract}

Correspondence to: Dr Katsuya Shiraki, First Department of Internal Medicine, Mie University School of Medicine, 2-174 Edobashi, Tsu, Mie 514-8507, Japan

E-mail: katsuyas@clin.medic.mie-u.ac-jp

Key words: COX-2 inhibitor, hepatocellular carcinoma, TRAIL, $\mathrm{TNF}$ decreased phospho-AKT in SK-Hep1 cells. These results demonstrate that COX-2 inhibitors can induce apoptosis and augment TRAIL sensitivity by up-regulation of TRAIL receptors and down-regulation of both survivin and AKT signaling.

\section{Introduction}

Hepatocellular carcinoma (HCC) is one of the most common malignancies worldwide, developing from the basic disease of chronic liver injury (1). In hepatocarcinogenesis, failure of apoptosis is considered to be important for the survival of hepatocytes, which may be more prone to genetic damage and cellular transformation via proliferation than other cell types since hepatocytes are a regenerative cell type. Indeed, most HCC cells show strong resistance to stimuli that induce apoptosis in other cells. Several cellular anti-apoptotic mechanisms are known to contribute to resistance against immunologic cytotoxicity in human HCC cells. These include up-regulation of anti-apoptotic proteins, members of the Bcl-2 family, and inhibitor of apoptosis family members such as X-chromosome-linked IAP (XIAP), survivin and FLICE-inhibitory proteins (FLIPs). Therefore, overcoming apoptotic resistance has become critical for the establishment of effective therapeutic strategies for the treatment of HCC.

Cyclooxygenases (COX) are key enzymes in the conversion of arachidonic acid to prostaglandins and other eicosanoids (2). There are two isoforms of COX; COX-1 and COX-2. COX-1 is constitutively expressed in various types of cells and plays important roles in homeostasis. COX-2 is usually absent under basal conditions but is inducible by various cytokines and growth factors and mitogens $(3,4)$. Interestingly, COX-2 has been shown to be upregulated in a variety of human cancers including colon, gastric, esophagus, pancreas, and breast cancer and in HCCs, despite the fact that COX-2 is undetectable in most normal tissue (5-10). In some cancers, such as colorectal carcinogenesis, COX-2 expression is present throughout carcinogenesis but during hepatocarcinogenesis, COX-2 expression is high in early stages of HCC but low in advanced stages. These findings suggest that COX-2 plays an important role in the early stages of hepatocarcinogenesis but not in advanced stages (11). Thus, COX-2 may be related to $\mathrm{HCC}$ dedifferentiation, an early event in hepatocarcinogenesis.

COX-2 induces at least three tumor-related processes. Firstly, it affects angiogenesis via an acceleration of production of both vascular and endothelial growth factor, and of 
prostaglandins (12). Secondly, it affects anti-apoptosis factors normally mediated by Bcl-2 and protein kinase B signaling (13-16). Thirdly, it has a strong effect on invasiveness via the action of matrix metalloproteinases. Selective COX-2 inhibitors such as NS398 can inhibit growth and induce apoptosis in several cancer cell types, including colon and pancreatic cancer cells. Moreover, a selective COX-2 inhibitor can inhibit growth and induce apoptosis in cultured colon and pancreatic cancer cell lines $(17,18)$. The antitumor effects of COX-2 inhibitors are also enhanced in combination therapy with conventional anticancer agents, radiotherapy, and photodynamic therapy (19-22). These findings might expand the therapeutic potential of COX-2 inhibitors. Nonetheless, the molecular and biochemical pathways responsible for the pro-apoptotic effects of COX-2 inhibitors remain poorly understood (17).

TNF-related apoptosis inducing ligand (TRAIL) is a member of the TNF family and selectively induces apoptosis in a variety of transformed cell lines. However, several tumor cell lines, including HCC and most normal cells, are resistant to TRAIL-mediated apoptosis. This selective effect on cancer cells is the basis of the current enthusiasm for TRAIL as a potential target of novel anticancer therapeutics. Previous studies have suggested that HCC cells might be resistant to TRAIL-mediated apoptosis, despite the fact that they express TRAIL receptors (23). Even if this proves true, it may be possible to sensitize HCC cells to TRAIL-induced apoptosis therefore, the study of how to bring about that sensitization is an important topic to be addressed.

In this study, we investigated the effects of COX-2 inhibitors on TRAIL sensitivity and looked at the molecular mechanisms of the action of COX-2 inhibitors with special attention to anti-apoptotic proteins using the highly selective COX-2 inhibitors, NS398 and 3-(4-methylsulphonylphenyl)4-phenyl-5-trifluoromethylisoxazole (CAY10404).

\section{Materials and methods}

Cell lines. The human HCC cell line, SK-Hep1, was purchased from the American Type Culture Collection (Rockville, MD) and HLE (JCRB 0404) was obtained from the Health Science Research Resources Bank (Osaka, Japan). All cell lines were maintained in Dulbecco's modified Eagle's medium (GibcoBRL, Grand Island, NY) with $10 \%$ heat inactivated fetal calf serum (Gibco-BRL) and 1\% penicillin/streptomycin (Gibco$\mathrm{BRL})$ in a humidified atmosphere containing $5 \% \mathrm{CO}_{2}$ at $37^{\circ} \mathrm{C}$.

Detection of proliferation. To assess HCC cell viability, the MTT assay [formally, the 3-(4,5-dimethylthiazol-2-yl)-2, 5-diphenyl tetrazolium bromide assay] was performed. HCC cells were plated at a density of $5 \times 10^{3}$ cells per well in 96-well microtiter plates (Corning Glass Works, Corning, NY) and each plate was incubated for $24 \mathrm{~h}$ at $37^{\circ} \mathrm{C}$ in $5 \% \mathrm{CO}_{2}$. The HCC cells were allowed to grow to a high density and then the cells were treated with COX-2 inhibitors CAY10404 or NS398 (Cayman Chemical, MI). The COX-2 inhibitors were added in the presence or absence of TRAIL (Santa Cruz Biotechnology, $\mathrm{CA}$ ) or TNF $\alpha$ (Genzyme-techne, Cambridge, MA) and the plates were incubated for $24 \mathrm{~h}$.
DAPI staining. Staining with DAPI (4'-6-diamidino-2phenylindole), a DNA-binding fluorescent dye, was performed as described. Briefly, after treatment with $50 \mu \mathrm{M}$ NS398 for 24 $\mathrm{h}$, the cells were washed three times with phosphate-buffered saline (PBS), and fixed first in $4 \%$ formaldehyde for $10 \mathrm{~min}$ and then in methanol. The cells were stained with $4 \mu \mathrm{g} / \mathrm{ml}$ DAPI (Roche, Germany) for $10 \mathrm{~min}$ and changes in nuclear morphology were observed by fluorescence microscopy.

Flow cytometric analysis. Approximately $1 \times 10^{6}$ SK-Hep1 cells incubated with $10 \mathrm{ng} / \mathrm{ml} \mathrm{COX}-2$ inhibitors $(100 \mu \mathrm{M}$ CAY10404, $50 \mu \mathrm{M}$ NS398) for $48 \mathrm{~h}$ were washed with PBS, harvested in the presence of $0.02 \%$ EDTA in PBS, and incubated for $30 \mathrm{~min}$ on ice with phycoerythrin (PE)conjugated anti-human TRAIL, isotype PE-conjugated mouse IgG, PE-conjugated anti-human DR4 (TRAIL-R1) and PEconjugated anti-human DR5 (TRAIL-R2; eBioscience, San Diego, CA) at a concentration of $5 \mu \mathrm{g} / \mathrm{ml}$. The cells were analyzed by flow cytometry using a FACScan cytometer and CellQuest software (Becton-Dickinson, Tokyo, Japan).

Immunoblotting. HCC cell extracts were homogenized in lysis buffer $(50 \mathrm{mmol} / 1$ Tris- $\mathrm{HCl} \mathrm{pH} 8.0,150 \mathrm{mmol} / \mathrm{l} \mathrm{NaCl}, 5 \mathrm{mmol} /$ 1 ethylenediaminetetraacetic acid, $1 \%$ NP-40, 1 mmol/l phenylmethylsulfonyl fluoride), and equal amounts of protein from each extract were separated by $14 \%$ sodium dodecyl sulfatepolyacrylamide gel electrophoresis (SDS-PAGE) and transferred to cellulose nitrate membranes (Advantec, Tokyo, Japan).

After blocking with $5 \%$ milk in Tris- $\mathrm{HCl}$ pH 7.5 with $0.1 \%$ Tween- 20 at $4^{\circ} \mathrm{C}$ overnight, the blots were incubated with $5 \mu \mathrm{g} / \mathrm{ml}$ anti-survivin antibody (Santa Cruz Biotechnology) or $10 \mu \mathrm{g} / \mathrm{ml}$ anti-survivin antibody pre-absorbed with survivin peptide resin overnight at $4^{\circ} \mathrm{C}$. In the same way, the blots were incubated with $5 \mu \mathrm{g} / \mathrm{ml}$ Anti-XIAP (BD Biosciences, MD), anti-Bcl-xL (BD Biosciences), anti-AKT or anti-phosphoAKT antibody pre-absorbed overnight at $4{ }^{\circ} \mathrm{C}$. The immunoblots were washed in Tris- $\mathrm{HCl} \mathrm{pH} 7.5$ with $0.1 \%$ Tween-20 and probed with horseradish peroxidase-conjugated anti-rabbit IgG (Bio-Rad Laboratories, Tokyo, Japan; 1:2,000 diluted with $5 \%$ milk in Tris- $\mathrm{HCl} \mathrm{pH} 7.5)$. After washing, the immunoblots were developed using the electrochemiluminescence system (Amersham, CA).

\section{Results}

COX-2 inhibitors induced apoptosis in HCC cells. To investigate the change in viability of $\mathrm{HCC}$ cells in response to $\mathrm{COX}-2$ inhibitors, $\mathrm{HCC}$ cells were incubated with various concentrations of COX-2 inhibitors for $48 \mathrm{~h}$. Cell viability was assessed using the MTT assay (Fig. 1). Cox-2 inhibitors caused a concentration-dependent decrease in cell viability in the two HCC cell lines tested, SK-hep1 and HLE. In order to ask if COX-2 inhibitors can induce apoptosis in HCC cells, we next looked at DAPI staining $24 \mathrm{~h}$ after treatment of SK-Hep1 cells with COX-2 inhibitors (Fig. 4). We found that COX-2 inhibitor-treated cells showed features typical of apoptosis, including nuclear condensation and nuclear fragmentation.

COX-2 inhibitors augmented TRAIL induced apoptosis. We further investigated TRAIL-induced apoptosis in HCC cells. 
a

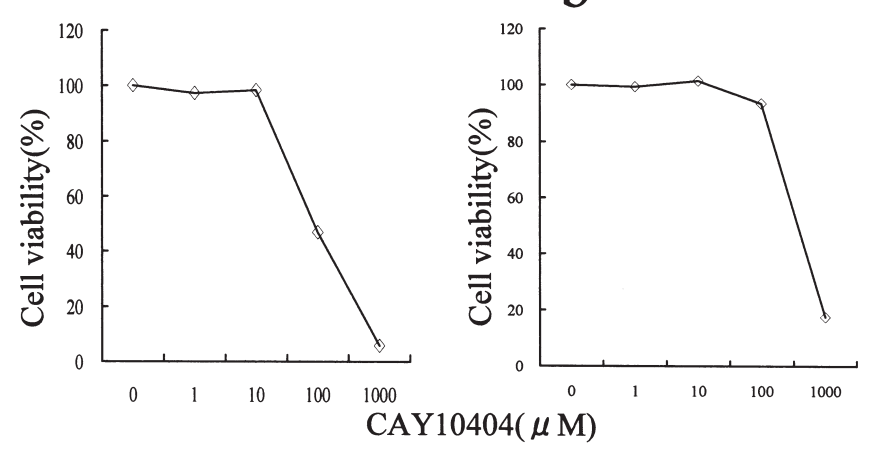

C

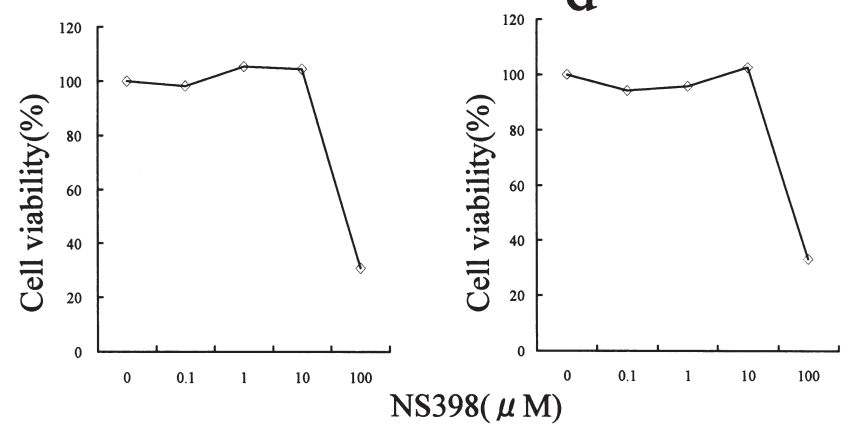

Figure 1. Cox-2 inhibitors induced cell death in human HCC cells. SK-Hep1 and HLE cells were treated with $0-1000 \mu \mathrm{M}$ CAY10404 or 0-100 $\mu \mathrm{M}$ NS398 and analyzed after $24 \mathrm{~h}$ for cell viability by the MTT assay. The data shown are representative of three independent experiments. (a) CAY10404 was added to SK-Hep1 cells. (b) CAY10404 was added to HLE cells. (c) NS398 was added to SK-Hep1 cells. (d) NS398 was added to HLE cells.

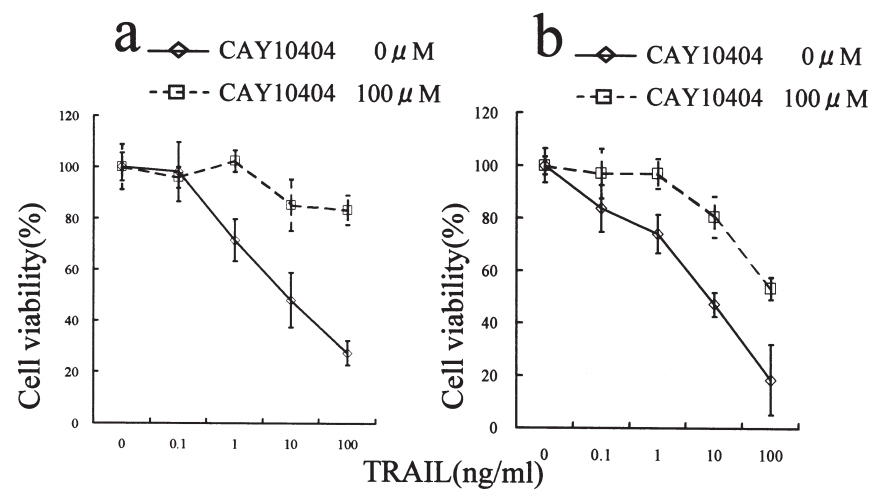

Figure 2. Treatment with both COX-inhibitors and TRAIL augmented cell death in HCC cells. SK-Hep1 and HLE cells were treated with $100 \mu \mathrm{M}$ CAY10404 or $0 \mu \mathrm{M}$ CAY 10404 and $0-100 \mathrm{ng} / \mathrm{ml}$ TRAIL or $0-100 \mathrm{ng} / \mathrm{ml}$ $\mathrm{TNF} \alpha$ and, after $24 \mathrm{~h}$, cell viability was assessed by the MTT assay. The data shown are representative of three independent experiments. $100 \mu \mathrm{M}$ CAY10404 or $0 \mu \mathrm{M}$ CAY10404 was added. (a) TRAIL was added to SK-Hep1 cells (b) TRAIL was added to HLE cells (c) TNF $\alpha$ was added to SK-Hep1 cell (d) TNF was added to HLE cells.

Unlike many other transformed cell lines, in HCC cells, TRAIL failed to induce apoptosis or even weak cytotoxicity, even at doses of up to $100 \mathrm{ng} / \mathrm{ml}$. However, in the presence of a sub-toxic level of COX-2 inhibitors (100 $\mu \mathrm{M}$ CAY10404 or $50 \mu \mathrm{M}$ NS398), TRAIL-treated cells demonstrated features typical of apoptosis; namely, nuclear condensation and nuclear
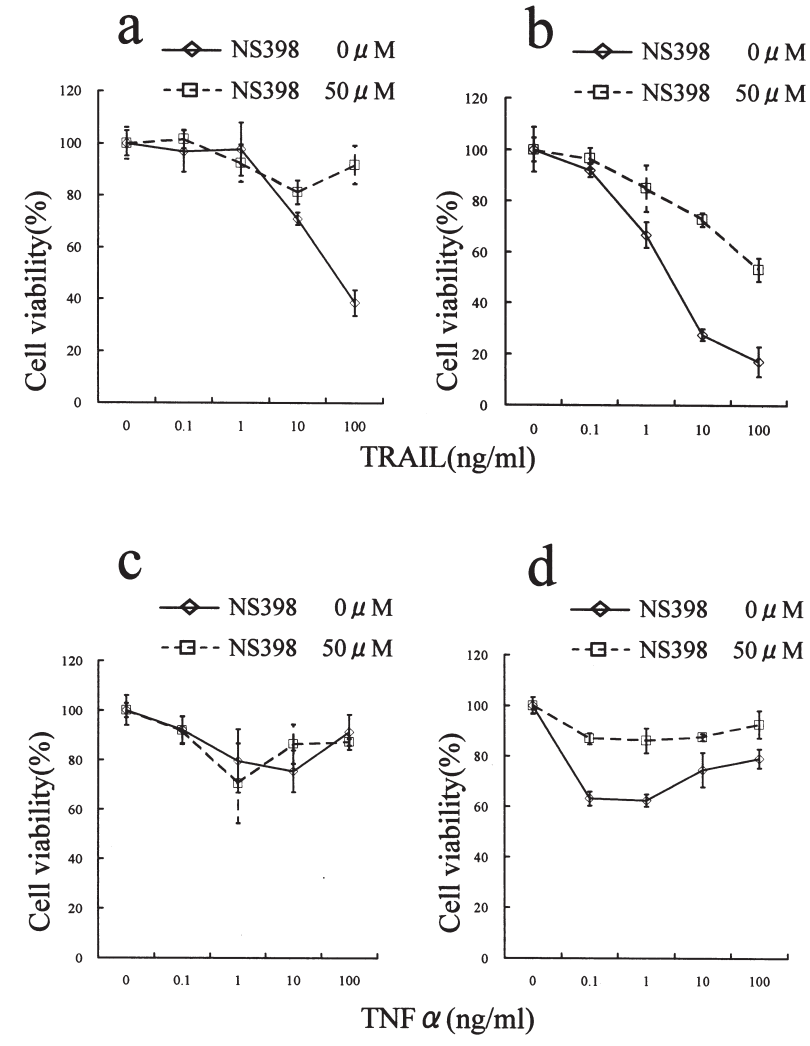

Figure 3. Treatment with both COX-inhibitors and TRAIL augmented cell death in HCC cells. SK-Hep1 and HLE cells were treated with $50 \mu \mathrm{M}$ NS398 or $0 \mu \mathrm{M}$ NS398 and $0-100 \mathrm{ng} / \mathrm{ml}$ TRAIL or $0-100 \mathrm{ng} / \mathrm{ml} \mathrm{TNF} \alpha$, and after $24 \mathrm{~h}$, cell viability was assessed by the MTT assay. The data shown are representative of three independent experiments. $50 \mu \mathrm{M}$ NS398 or $0 \mu \mathrm{M}$ NS398 was added. (a) TRAIL was added to SK-Hep1 cells (b) TRAIL was added to HLE cells (c) TNF $\alpha$ was added to SK-Hep1 cells (d) TNF $\alpha$ was added to HLE cells.

fragmentation (Fig. 4). Treatment with COX-2 inhibitors converted TRAIL-resistant cells into TRAIL-sensitive cells, resulting in TRAIL-induced apoptosis in both HCC cells that was dependent on the concentration of COX-2 inhibitors. Viability of cells $24 \mathrm{~h}$ after treatment with TRAIL (100 ng/ml) in the presence of COX-2 inhibitors (100 $\mu \mathrm{M}$ CAY 10404 or $50 \mu \mathrm{M}$ NS398) was 27\% (CAY10404, SK-Hep1), $18 \%$ (CAY10404, HLE), 38\% (NS398, SK-Hep1) or 17\% (NS398, HLE). Despite this ability to sensitize cells to TRAIL-mediated apoptosis, COX-2 inhibitors did not affect TNFa-induced apoptosis in both cells (Figs. 2 and 3).

COX-2 inhibitors up-regulated TRAIL receptors. In order to examine the mechanisms of increased TRAIL susceptibility in SK-Hep1 and HLE cells, cell surface expression of TRAIL and its receptors was investigated using flow cytometry analysis (Fig. 5). We found that, in SK-Hep1 and HLE cells incubated with COX-2 inhibitors for $48 \mathrm{~h}$, TRAIL-R2/DR5 expression was significantly up-regulated (SK-Hep1 cells) or slightly up-regulated (HLE cells). In addition, TRAIL-R1/DR4 expression was slightly up-regulated in SK-Hep1 cells. However, cell surface expression of TRAIL was not upregulated in either cell type.

COX-2 inhibitors affected apoptosis regulatory proteins. $\mathrm{Bcl}-\mathrm{xL}$, a mitochondrial apoptosis inhibitory protein, and 
a

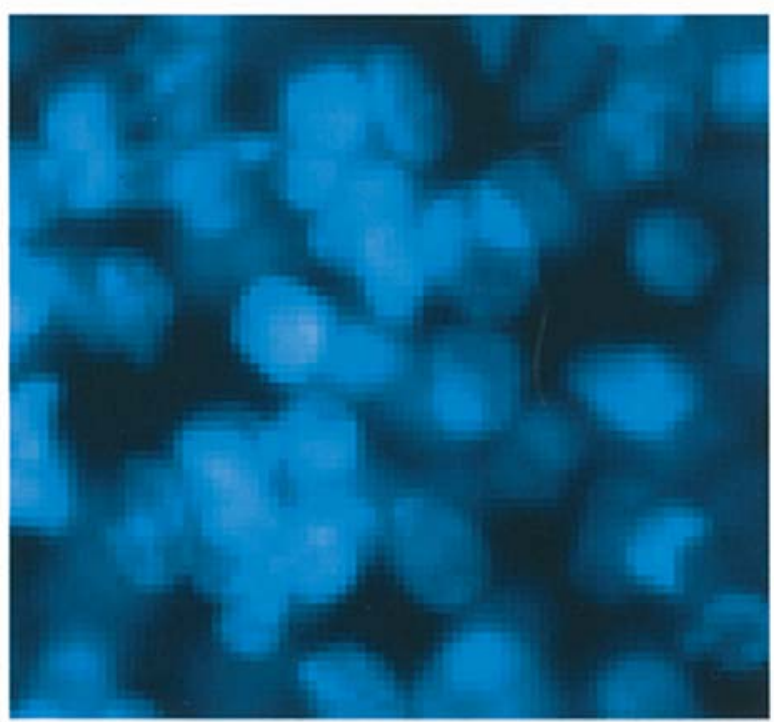

$\mathrm{C}$

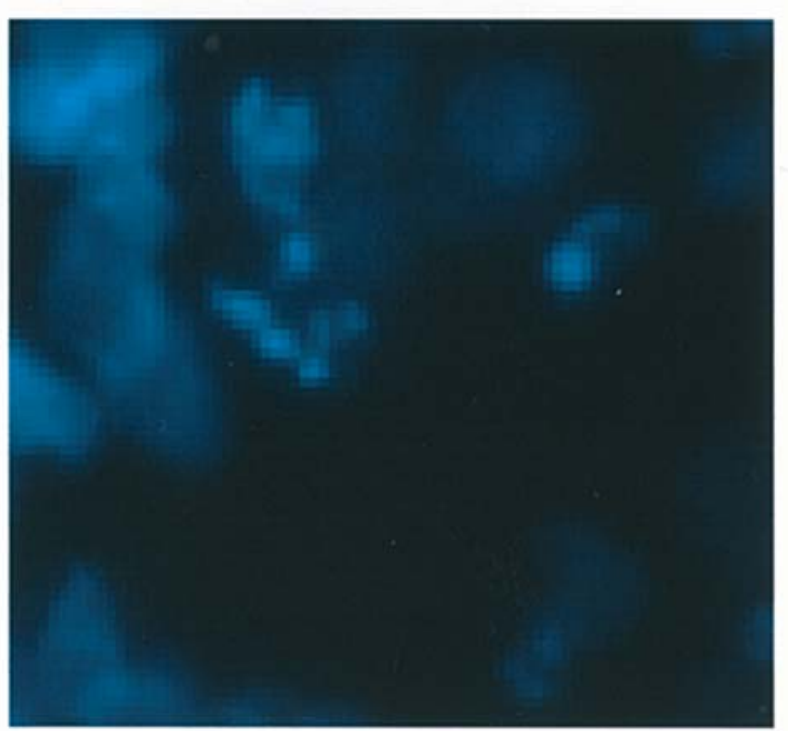

b

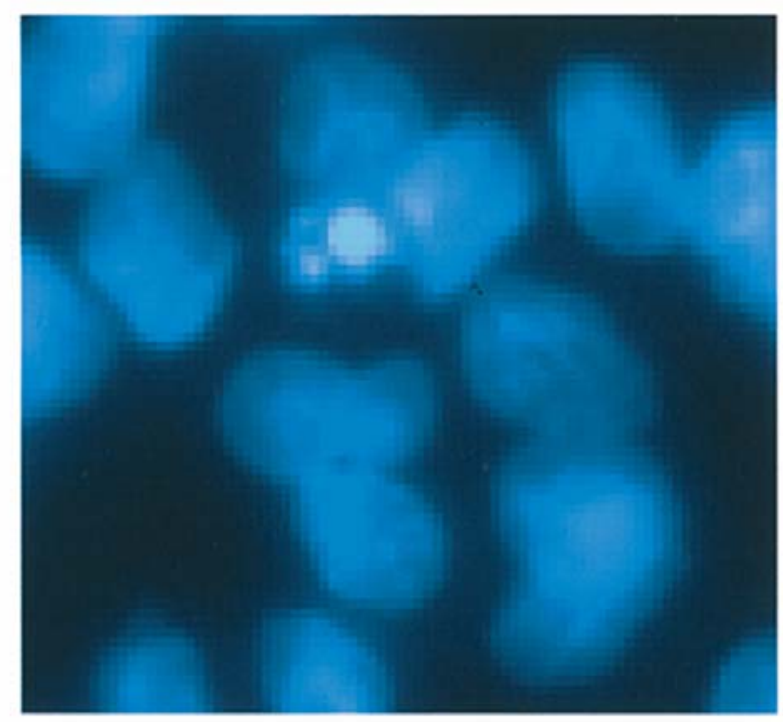

d

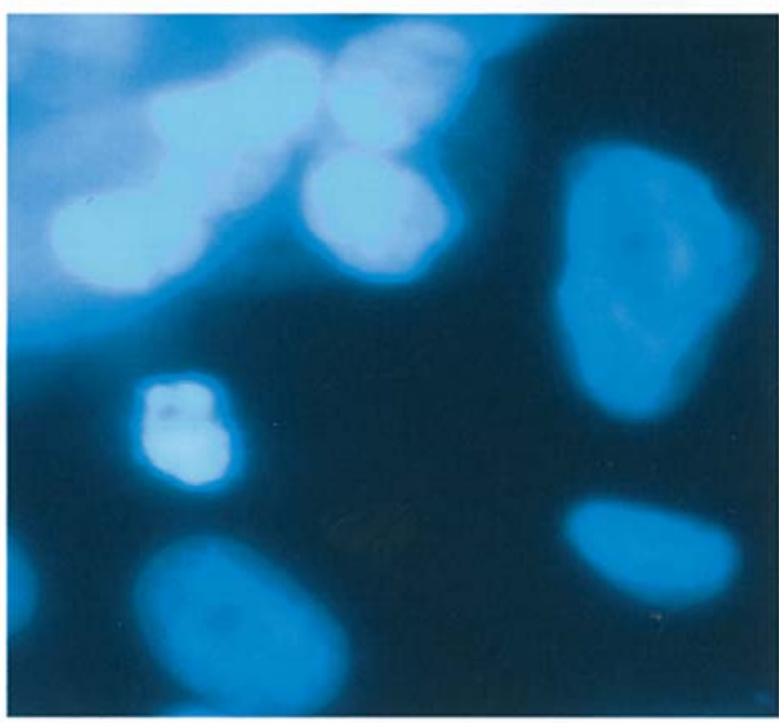

Figure 4. COX-2 and TRAIL inhibitors induced apoptosis in SK-Hep1 cells. Cells were cultured in the (a) absence, or (b) presence of $100 \mu$ M CAY10404, (c) $50 \mu \mathrm{M} \mathrm{NS} 398$ and (d) $100 \mu \mathrm{M}$ CAY10404 and $10 \mathrm{ng} / \mathrm{ml}$ TRAIL for $24 \mathrm{~h}$. Cell nuclei were stained with DAPI. Note the feathers of nuclear condensation and nuclear fragmentation typical of apoptotic cells (b, c and d).

survivin and XIAP, direct inhibitors of cell-death proteases, play major roles in the control of apoptotic pathways. To determine the expression levels of these apoptosis-related proteins in HCC cells, we analyzed their expression by immunoblotting (Figs. 6 and 7). Expression of survivin and Bcl-xL was down-regulated in SK-Hep1 and HLE cells in the presence of CAY10404 but XIAP was not affected. Expression of survivin, Bcl-xL and XIAP was down-regulated in SK-Hep1 cells in the presence of NS398. Survivin expression was also down-regulated in the presence of NS398 in HLE cells.

COX-2 inhibitors modulate the AKT pathway. Finally, we investigated the state of the AKT pathway, since the pathway is important for the balance between cell survival and apoptosis. To determine whether TI3K/AKT signaling pathways are involved in COX-2 inhibitors-induced apoptosis, we looked at AKT phosphorylation by immunoblotting (Fig. 8). NS398 treatment resulted in a significant and dose-dependent decrease in the level of phosphorylation of AKT in SK-Hep1 cells but did not have an affect on AKT activity in HLE cells.

\section{Discussion}

We show that COX-2 inhibitors NS398 and CAY10404 induced apoptosis in two HCC cell types tested and that the effect was concentration dependent. Previous studies have shown that NS398, a selective COX-2 inhibitor, can inhibit growth and induce apoptosis in several other cancer cell lines, 

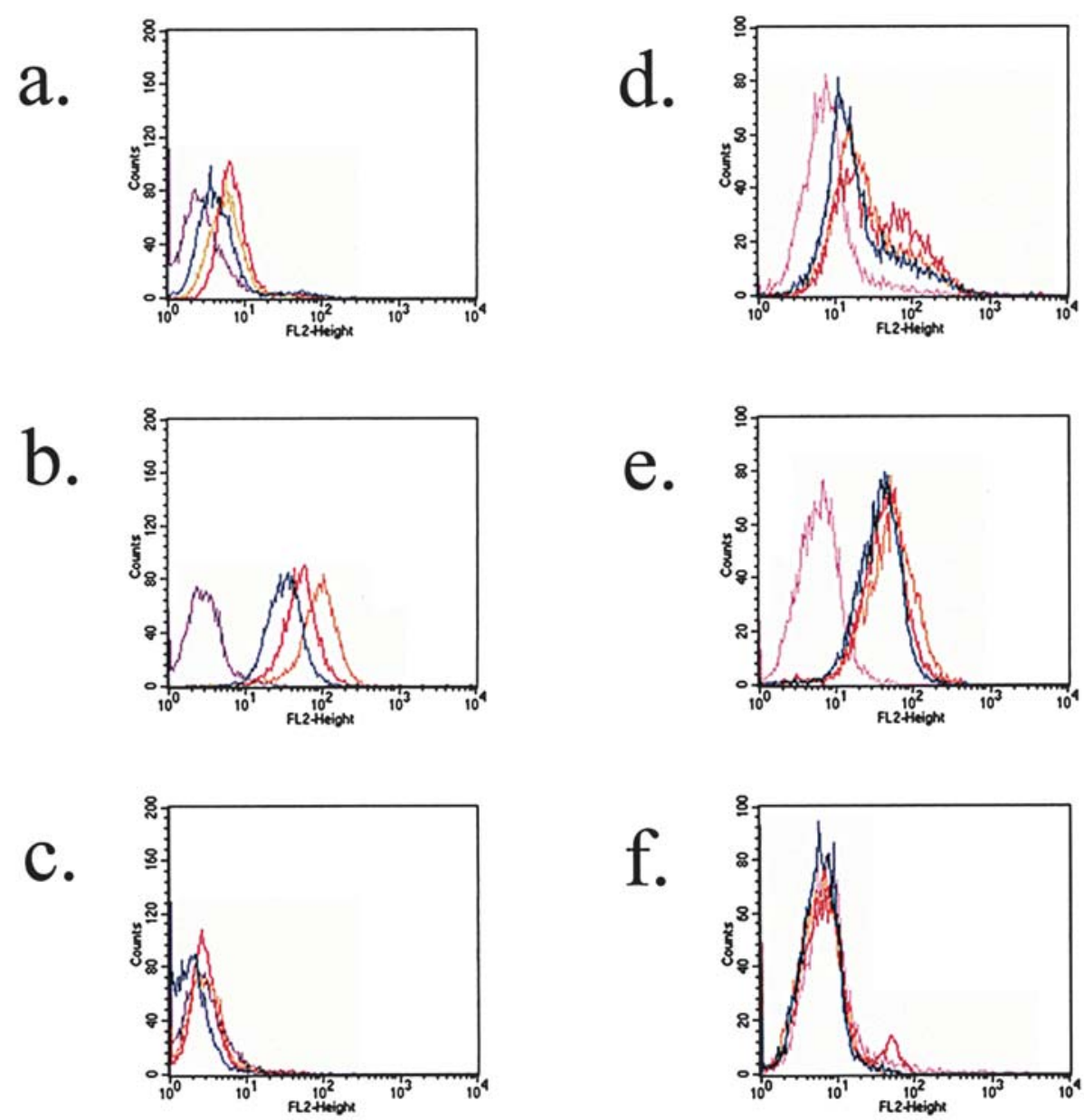

Figure 5. TRAIL-R2/DR5 expression was significantly up-regulated (SK-Hep1 cells) or slightly up-regulated (HLE cells). TRAIL-R1/DR4 expression was slightly up-regulated in SK-Hep1 cells. TRAIL expression was not up-regulated in either cell type. HCC cells were incubated with $100 \mu$ M CAY10404 (red lines) or $50 \mu \mathrm{M}$ NS398 (orange lines) for $24 \mathrm{~h}$, and were then stained with PE-anti-human TRAIL-R1/DR4 [(a) SH-Hep1 cells, (d) HLE cells], TRAILR2/DR5 [(b) SK-Hep1 cells, (d) HLE cells], or TRAIL [(c) SK-Hep1 cells, (f) HLE cells]. Control cells were not treated (blue lines). Auto-fluorescence and non-specific staining were determined using cells incubated with PE-control mouse IgG (purple lines).

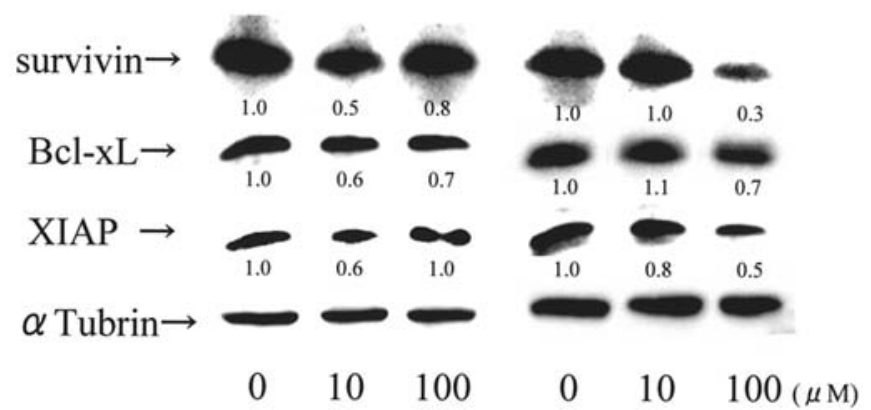

Figure 6. Expression of survivin, Bcl-xL, and XIAP in SK-Hep1 cells after treatment with COX-2 inhibitors. SK-Hep1 cells were incubated with COX-2 inhibitors at the indicated concentrations. The cellular lysates were analyzed by SDS-PAGE and immunoblotting. The amount of sirvivin, Bcl-xL and XIAP was quantified by densitometric analysis and was calculated in relation to the control cell after normalizing for the amount of atubulin. The ratio was presented below the band.

and a variety of anti-tumor effects that might be exerted by COX-2 inhibitors have been proposed (17). For example, the anti-tumor effects of selective COX-2 inhibitors have been attributed to both anti-angiogenesis and pro-apoptosis

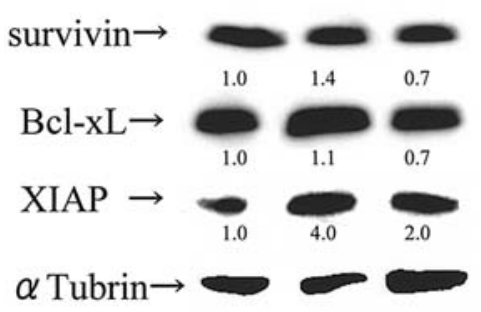

$0 \quad 10 \quad 100$

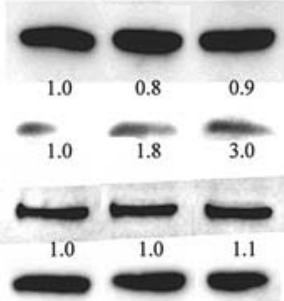

$0 \quad 10100(\mu \mathrm{M})$
Figure 7. Expression of survivin, Bcl-xL, and XIAP in HLE cells after treatment with COX-2 inhibitors. HLE cells were incubated with COX-2 inhibitors at the indicated concentrations. The cellular lysates were analyzed by SDS-PAGE and immunoblotting. The amount of sirvivin, Bcl-xL and XIAP was quantified by densitometric analysis and was calculated in relation to the control cell after normalizing for the amount of atubulin. The ratio was presented below the band.

mechanisms (12). Indeed, COX-2 induces angio-genesis through accelerated production of both vascular endothelial growth factor (VEGF) and prostaglandins (24-26). Elevated expression of COX-2 in tumors is associated with an 

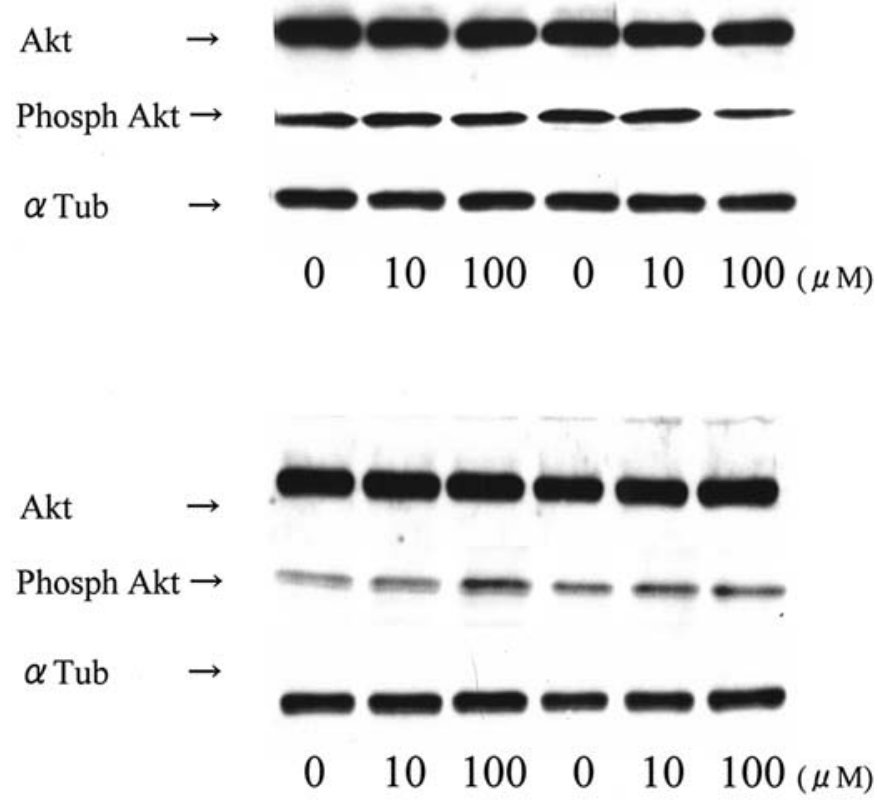

Figure 8. Expression of AKT and phospho-AKT in HCC cells. SK-Hep1 and HLE cells were incubated with COX-2 inhibitors at the indicated concentrations. The cellular lysates were analyzed by SDS-PAGE and immunoblotting.

increase in angiogenesis, invasiveness, and resistance to apoptosis. Moreover, COX inhibitors caused an increase in the detectable levels of the von Hippel Lindau protein, which participates in ubiquitination of the hypoxiainducible factor- $1 \alpha$ (HIF-1 $\alpha)$ protein and eventually leads to down-regulation of VEGF via HIF-1 $\alpha$ degradation (27). In addition, COX inhibitors are known to act as agonists for peroxisome proliferator-activated receptors (PPARs) $\alpha$ and $\gamma$, which are members of the nuclear hormone receptor superfamily. COX inhibitors have strong anti-inflammatory and anti-angiogenic effects, extending the repertoire of potential targets of PPAR $\gamma$ ligands beyond cell autonomous mechanisms of cancer. However, the molecular and biochemical pathways responsible for the apoptotic effects of COX-2 inhibitors remain poorly understood.

Previous studies have shown that although most HCC cell lines are resistant to TRAIL, co-treatment of chemotherapeutic agents and irradiation made TRAIL-resistant cells sensitive to TRAIL. We have found that subcytotoxic levels' of COX-2 inhibitors sensitize HCC cells to TRAIL-induced apoptosis. These results suggest that COX-2 inhibitors modulate the apoptotic pathway to bring about an increase in cell sensitivity to TRAIL receptor-mediated signaling. In support of this idea, we found that COX-2 inhibitors caused a significant upregulation of TRAIL-R2/DR5 and, to a lesser extent, upregulated TRAIL-R1/DR4. Previous reports also suggested that, in human colon cancer cell lines, overexpression of COX-2 inhibitors reduces TRAIL-R2/DR5 mRNA and protein whereas sulindac sulfide increased both TRAIL-R1/DR4 and TRAIL-R2/DR5 mRNA (30,31). Induction of TRAIL-R1/DR4 and TRAIL-R2/DR5 mRNA following DNA damage is dependent on the presence of wild-type p53; however, in our study, SK-Hep1 and HLE, which lack a wild-type copy of p53, both exhibited TRAIL-
R1/DR4 and TRAIL-R2/DR5 up-regulation. These results provide support for the idea that up-regulation of TRAILR1/DR4 and TRAIL-R2/DR5 by COX-2 inhibitors is p53independent. Moreover, activation of TRAIL-R2/DR5 has been shown to increase TRAIL-induced apoptosis both in vitro and in vivo, indicating that it is primarily TRAIL-R2/DR5 that determines the apoptotic sensitivity of TRAIL (32). Therefore, the fact that we found an increase in TRAIL-R2/DR5 expression after treatment of HCC cells with COX-2 inhibitors could explain the increase in TRAIL sensitivity.

We next looked at the inhibitors of apoptosis proteins (IAPs) in TRAIL signaling, since these proteins plays an important role in determining the sensitivity of apoptosis in HCC cells. The strongest evidence for the involvement of IAP family proteins in cancer has been found for two family members, survivin and XIAP $(33,34)$.

We found that both inhibitors were able to cause a significant down-regulation of survivin in both of the cell lines. In addition, we have shown that survivin is overexpressed in human HCC and that it is a principal inhibitor of apoptosis, presumably via its ability to inhibit caspase- 3 and -7 . Previous studies suggested that survivin can directly bind to caspases. From our results, we conclude that down-regulation of levels of survivin protein by COX-2 inhibitors is one cause of the increase in TRAIL-induced apoptosis that we observed for HCC cells. Interestingly, another IAP, XIAP, was also downregulated by NS398 in SK-Hep1. Suppression of survivin by COX-2 inhibitors has also been reported in non-small cell lung cancer cells. Further study will be needed to understand how these IAP family proteins are regulated by COX-2 inhibitors (35).

Protein levels of the other caspase inhibitor, Bcl-xL, were also significantly down-regulated by treatment with the COX-2 inhibitors. Most anticancer drugs induce apoptosis by engaging the mitochondrial pathway, which is regulated by $\mathrm{Bcl}-2$ family proteins. $\mathrm{Bcl}-\mathrm{xL}$ is overexpressed in human $\mathrm{HCC}$ cells and has been shown to be a principal anti-apoptotic factor induced by cellular stresses such as staurosporine treatment, serum starvation, and p53 activation. Thus, we consider down-regulation of Bcl-xL another important cause of the augmentation of TRAIL-induced apoptosis.

Finally, we investigated the AKT pathway, since the serine/threonine kinase AKT (protein kinase B) is a regulator of cell survival and apoptosis, and its activation has been shown to protect a variety of cells against apoptosis. AKT promotes cell survival by inhibiting apoptosis through its ability to phosphorylate and inactivate several targets, including BAD and caspase-9. Our study demonstrated that the level of phosphorylated AKT was reduced by NS398 in SK-Hep1. Recently, celecoxib was reported to induce apoptosis by blocking the activation of anti-apoptotic AKT in prostate cancer cells via an action that is independent of Bcl-2 (36). Previous studies also indicated that, of six selective COX-2 inhibitors, only celecoxib caused a decrease in the level of phospho-AKT in HT-29 and SW-480 cells (37). However, the mechanism by which celecoxib suppresses AKT phosphorylation is still unknown, although celecoxib inhibited PDK1 and PTEN phosphorylation in cholangiocarcinoma cells (38). Thus, inhibition of AKT phosphorylation may be dependent on which COX-2 inhibitor is tested and on cell-type. 
In conclusion, we demonstrated that COX-2 inhibitors can induce apoptosis and augment TRAIL sensitivity by upregulation of TRAIL receptors and down-regulation of survivin and AKT pathway signaling. Since sensitivity to apoptosis is closely related to resistance to conventional anticancer agents, radiotherapy, and photodynamic therapy, these results suggest that combining COX-2 inhibitors with a TRAIL agonist or other anti-cancer therapies may prove to be an effective new strategy for treatment of HCC.

\section{References}

1. Hu KQ: Rationale and feasibility of chemoprovention of hepatocellular carcinoma by cyclooxygenase-2 inhibitors. J Lab Clin Med 139: 234-243, 2002.

2. Williams CS, Smalley W and DuBois RN: Aspirin use and potential mechanisms for colorectal cancer prevention. J Clin Invest 100: 1325-1329, 1997.

3. Buttar NS and Wang KK: The 'aspirin' of the new millennium: cyclooxygenase-2 inhibitors. Mayo Clin Proc 75: 1027-1038, 2000.

4. Fosslien E: Biochemistry of cyclooxygenase (COX)-2 inhibitors and molecular pathology of COX-2 in neoplasia. Crit Rev Clin Lab Sci 37: 431-502, 2000.

5. Totzke G, Schulze-Osthoff $\mathrm{K}$ and Janicke RU: Cyclooxygenase-2 (COX-2) inhibitors sensitize tumor cells specifically to death receptor-induced apoptosis independently of COX-2 inhibition. Oncogene 22: 8021-8030, 2003.

6. Eberhart CE, Coffey RJ, Radhika A, Giardiello FM, Ferrenbach S and DuBois RN: Up-regulation of cyclooxygenase-2 gene expression in human colorectal adenomas and adenocarcinomas. Gastroenterology 107: 1183-1188, 1994.

7. Hida T, Yatabe Y, Achiwa H, Muramatsu H, Kozaki K, Nakamura S, Ogawa M, Mitsudomi T, Sugiura T and Takahashi T: Increased expression of cyclooxygenase- 2 occurs frequently in human lung cancers, specifically in adenocarcinomas. Cancer Res 58: 3761-3764, 1998 .

8. Ristimaki A, Honkanen N, Jankala H, Sipponen $\mathrm{P}$ and Harkonen M: Expression of cyclooxygenase-2 in human gastric carcinoma. Cancer Res 57: 1276-1280, 1997.

9. Tucker ON, Dannenberg AJ, Yang EK, Zhang F, Teng L, Daly JM, Soslow RA, Masferrer JL, Woerner BM, Koki AT and Fahey TJ III: Cyclooxygenase-2 expression is up-regulated in human pancreatic cancer. Cancer Res 59: 987-990, 1999.

10. Zimmermann KC, Sarbia M, Weber AA, Borchard F, Gabbert HE and Schror K: Cyclooxygenase-2 expression in human esophageal carcinoma. Cancer Res 59: 198-204, 1999.

11. Qiu DK, Ma X, Peng YS and Chen XY: Significance of cyclooxygenase-2 expression in human primary hepatocellular carcinoma. World J Gastroenterol 8: 815-817, 2002.

12. Koga $\mathrm{H}$ : Hepatocellular carcinoma: Is there a potential for chemoprevention using cyclooxygenase-2 inhibitors? Cancer 98: 661-667, 2003.

13. Sheng H, Shao J, Morrow JD, Beauchamp RD and DuBois RN: Modulation of apoptosis and Bcl-2 expression by prostaglandin E2 in human colon cancer cells. Cancer Res 58: 362-366, 1998.

14. Liu CH, Chang SH, Narko K, et al: Overexpression of cyclooxygenase- 2 is sufficient to induce tumorigenesis in transgenic mice. J Biol Chem 21: 18563-18569, 2001.

15. Sheng H, Shao J and DuBois RN: K-Ras-mediated increase in cyclooxygenase- 2 mRNA stability involves activation of the protein kinase B1. Cancer Res 61: 2670-2675, 2001.

16. Nzeako UC, Guicciardi ME, Yoon JH, Bronk SF and Gores GJ: COX-2 inhibits Fas-mediated apoptosis in cholangiocarcinoma cells. Hepatology 35: 552-559, 2002.

17. Sun Y, Tang XM, Half E, Kuo MT and Sinicrope FA: Cyclooxygenase-2 overexpression reduces apoptotic susceptibility by inhibiting the cytochrome c-dependent apoptotic pathway in human colon cancer cells. Cancer Res 62: 6323-6328, 2002.

18. Jia XQ, Zhong N, Han LH, Wang JH, Yan M, Meng FL and Zhang SZ: Effect of NS-398 on colon cancer cells. World J Gastroenterol 11: 353-356, 2005

19. Hida T, Kozaki K, Ito H, et al: Significant growth inhibition of human lung cancer cells both in vitro and in vivo by the combined use of a selective cyclooxygenase 2 inhibitor, JTE-522, and conventional anticancer agents. Clin Cancer Res 8: 2442-2447, 2002.
20. Petersen C, Petersen S, Milas L, Lang FF and Tofilon PJ: Enhancement of intrinsic tumor cell radiosensitivity induced by a selective cyclooxygenase-2 inhibitor. Clin Cancer Res 6: 25132520, 2000.

21. Pyo H, Choy H, Amorino GP, et al: A selective cyclooxygenase-2 inhibitor, NS-398, enhances the effect of radiation in vitro and in vivo preferentially on the cells that express cyclooxygenase- 2 . Clin Cancer Res 7: 2998-3005, 2001.

22. Ferrario A, Von Tiehl K, Wong S, Luna M and Gomer CJ: Cyclooxygenase-2 inhibitor treatment enhances photodynamic therapy-mediated tumor response. Cancer Res 62: 3956-3961, 2002.

23. Yamanaka T, Shiraki K, Sugimoto K, Ito T, Fujikawa K, Ito M, Takase K, Moriyama M, Nakano T and Suzuki A: Chemotherapeutic agents augment TRAIL-induced apoptosis in human hepatocellular carcinoma cell lines. Hepatology 32: 482-490, 2000 .

24. Bamba H, Ota S, Kato A, Kawamoto C and Fujiwara K: Prostaglandins up-regulate vascular endothelial growth factor production through distinct pathways in differentiated U937 cells. Biochem Biophys Res Commun 273: 485-491, 2000.

25. Murono $\mathrm{S}$, Inoue $\mathrm{H}$, Tanabe $\mathrm{T}$, et al: Induction of cyclooxygenase- 2 by Epstein-Barr virus latent membrane protein 1 is involved in vascular endothelial growth factor production in nasopharyngeal carcinoma cells. Proc Natl Acad Sci USA 8: 6905-6910, 2001.

26. Cianchi F, Cortesini C, Bechi $\mathrm{P}$, et al: Up-regulation of cyclooxygenase- 2 gene expression correlates with tumor angiogenesis in human colorectal cancer. Gastroenterology 121: 1339-1347, 2001.

27. Jones MK, Szabo IL, Kawanaka H, Husain SS and Tarnawski AS: von Hippel Lindau tumor suppressor and HIF-1: new targets of NSAIDs inhibition of hypoxia-induced angiogenesis. FASEB J 16: 264-266, 2002.

28. Lehmann JM, Lenhard JM, Oliver BB, Ringold GM and Kliewer SA: Peroxisome proliferator-activated receptors $\alpha$ and $\gamma$ are activated by indomethacin and other non-steroidal antiinflammatory drugs. J Biol Chem 272: 3406-3410, 1997.

29. Jaradat MS, Wongsud B, Phornchirasilp S, et al: Activation of peroxisome proliferator-activated receptor isoforms and inhibition of prostaglandin $\mathrm{H} 2$ synthases by ibuprofen, naproxen, and indomethacin. Biochem Pharmacol 62: 1587-1595, 2001.

30. He Q, Luo X, Huang Y and Sheikh MS: Apo2L/TRAIL differentially modulates the apoptotic effects of sulindac and a COX-2 selective non-steroidal anti-inflammatory agent in Baxdeficient cells. Oncogene 21: 6032-6040, 2002.

31. Huang Y, He Q, Hillman MJ, Rong R and Sheikh MS: Sulindac sulfide-induced apoptosis involves death receptor 5 and the caspase 8-dependent pathway in human colon and prostate cancer cells. Cancer Res 61: 6918-6924, 2001.

32. Ichikawa K, Liu W, Zhao L, Wang Z, Liu D, Ohtsuka T, Zhang H, Mountz JD, Koopman WJ, Kimberly RP and Zhou T: Tumoricidal activity of a novel anti-human DR5 monoclonal antibody without hepatocyte cytotoxicity. Nat Med 7: 954-960, 2001.

33. Ito T, Shiraki K, Sugimoto K, Yamanaka T, Fujikawa K, Ito M, Takase K, Moriyama M, Kawano H, Hayashida M, Nakano T and Suzuki A: Survivin promotes cell proliferation in human hepatocellular carcinoma. Hepatology 31: 1080-1085, 2000.

34. Shiraki K, Sugimoto K, Yamanaka Y, Yamaguchi Y, Saitou Y Ito K, Yamamoto N, Yamanaka T, Fujikawa K, Murata K and Nakano T: Overexpression of X-linked inhibitor of apoptosis in human hepatocellular carcinoma. Int J Mol Med 12: 705-708, 2003.

35. Krysan K, Dalwadi H, Sharma S, Pold M and Dubinett S: Cyclooxygenase-2-dependent expression of survivin is critical for apoptosis resistance in non-small cell lung cancer. Cancer Res 64: 6359-6362, 2004

36. Hsu AL, Ching TT, Wang DS, Song X, Rangnekar VM and Chen CS: The cyclooxygenase-2 inhibitor celecoxib induces apoptosis by blocking Akt activation in human prostate cancer cells independently of Bcl-2. J Biol Chem 275: 11397-11403, 2000.

37. Yamazaki R, Kusunoki N, Matsuzaki T, Hashimoto S and Kawai S: Selective cyclooxygenase-2 inhibitors show a differential ability to inhibit proliferation and induce apoptosis of colon adenocarcinoma cells. FEBS Lett 531: 278-284, 2002.

38. Wu T, Leng J, Han C and Demetris AJ: The cyclooxygenase-2 inhibitor celecoxib blocks phosphorylation of Akt and induces apoptosis in human cholangiocarcinoma cells. Mol Cancer Ther 3: 299-3307, 2004. 